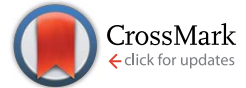

Cite this: RSC Adv., 2017, 7, 15112

21st January 2017

Accepted 20th February 2017

DOI: $10.1039 / \mathrm{c} 7 \mathrm{ra00913e}$

rsc.li/rsc-advances

\section{Highly emissive carbazole-based gold(I) complex with a long room-temperature phosphorescence lifetime and self-reversible mechanochromism characteristics $\dagger$}

\author{
Zhao Chen, Gang Liu, Renjie Wang and Shouzhi Pu*
}

We report a highly emissive carbazole-based mononuclear gold(I) complex. Its solid shows a long roomtemperature phosphorescence lifetime up to $29.91 \mathrm{~ms}$. Furthermore, the luminogen exhibits selfreversible mechanochromic behavior.
The synthesis of efficient luminogenic materials is a hot and popular research topic. ${ }^{1}$ Of particular interest are those luminescent materials that exhibit a luminescence response to external mechanical stimuli because of their potential practical applications in various areas, such as fluorescence sensors, data storage and optoelectronic devices. ${ }^{2}$ In recent years, mechanical-stimuli-responsive materials have been generally regarded as extremely "smart" materials; this is because the external mechanical force is one of the most common stimuli, and it can be easily modulated. ${ }^{3}$ Bright solid-state luminescence and an obvious color contrast upon grinding are two very important factors for the practical application of mechanochromic materials. ${ }^{4}$ To date, a lot of mechanochromic luminogens based on organic compounds have been reported. ${ }^{5}$ In contrast, metal complexes with mechanochromic behavior are rare. In the last decade, gold(I) chemistry has attracted substantial interest, ${ }^{6}$ and $\operatorname{gold}(\mathrm{I})$ complexes with mechanochromism properties have received a lot of attention. ${ }^{7}$ However, the number of gold(I) complexes exhibiting mechanochromism behavior is still insufficient. Furthermore, the majority of reported mechanochromic gold(I) complexes are known to a contain pentafluorophenyl unit. ${ }^{8}$

It is well known that compounds with carbazole skeletons are very valuable candidates in the domain of optoelectronic devices. ${ }^{9}$ Unfortunately, the notorious aggregation-caused quenching (ACQ) phenomenon leads to the poor solid-state emission efficiency of numerous luminescent molecules. ${ }^{10}$ Indeed, the luminous efficiency of many carbazole-based luminescent molecules in the solid state generally decreases with the formation of crystalline state, which is

Jiangxi Key Laboratory of Organic Chemistry, Jiangxi Science and Technology Normal University, Nanchang 330013, PR China. E-mail: pushouzhi@tsinghua.org.cn; Fax: +86-791-83831996; Tel: +86-791-83831996

$\dagger$ Electronic supplementary information (ESI) available: Detailed experimental section, NMR spectra, mass spectra and characterization datas mentioned in the paper. See DOI: 10.1039/c7ra00913e disadvantageous for efficient application of these carbazolebased derivatives. To date, carbazole-based mechanochromic gold(I) complexes are quite scarce. ${ }^{11}$ Therefore, it is urgent and challenging to develop highly solid-state emissive carbazolebased mechanochromic gold(I) complexes. On the other hand, it is meaningful to synthesize luminescent molecules with a long room-temperature phosphorescence (RTP) lifetime. ${ }^{12}$ Meanwhile, it is also valuable for fundamental research and practical applications of mechanochromism materials to achieve spontaneous recovery of their mechanochromic luminescence without using any stimuli. ${ }^{13}$ For example, self-reversible mechanochromism materials can be used to realize dynamic random access memory (DRAM) ${ }^{14}$

In this article, we demonstrate a highly emissive carbazolebased gold(I) complex 1 with a long RTP lifetime (Scheme 1). The luminogen 1 exhibits mechanochromic behavior involving the luminescence changes between yellow and yellow-green emissions. More interestingly, the mechanochromic luminescence of $\mathbf{1}$ can be restored to the initial color spontaneously without applying other stimuli.

Gold(I) complex 1 was synthesized as a white solid in accordance with the simple and reasonable synthetic strategy shown in Scheme S1 (ESI $\dagger$ ). Intermediate product 1-d as starting material reacted with $\mathrm{AuCl}(\mathrm{tht})$ (tht = thiophane) to afford the target mononuclear gold(I) complex 1 in $81 \%$ yield. The corresponding information about the synthetic procedures and characterization of luminogen $\mathbf{1}$ can be found in the ESI. $\dagger$

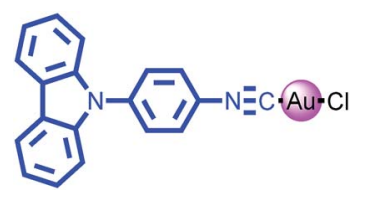

Scheme 1 The structure of complex 1. 

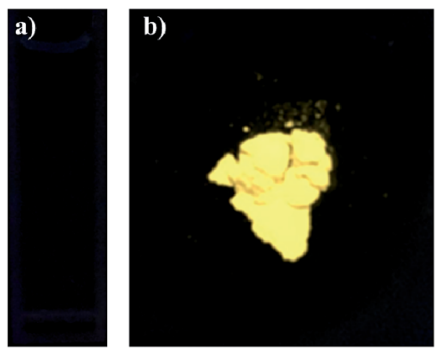

Fig. 1 (a) Luminescence image of $1\left(1.0 \times 10^{-5} \mathrm{~mol} \mathrm{~L}^{-1}\right)$ in pure DMF. Excitation wavelength: $365 \mathrm{~nm}$. (b) Luminescence image of the assynthesized solid sample 1. Excitation wavelength: $365 \mathrm{~nm}$.

We initially evaluated the luminescence behavior of 1 in various states. As can be seen in Fig. 1, luminogen $1(1.0 \times$ $10^{-5} \mathrm{~mol} \mathrm{~L}^{-1}$ ) in pure DMF exhibited very weak luminescence under $365 \mathrm{~nm}$ UV light, and its absolute luminescence quantum yield was $2.2 \%$, likely due to the rotation of carbazole unit, which consumes the bulk of the energy of the excited state. ${ }^{15}$ However, the solid sample of $\mathbf{1}$ showed a bright yellow luminescence under $365 \mathrm{~nm}$ UV light with an absolute luminescence quantum yield up to $33.8 \%$, the bright yellow emission of complex 1 in solid state is possibly triggered by the synergistic effects of the restricted intramolecular rotation of carbazole unit and the formation of intermolecular gold-gold interactions. ${ }^{\mathbf{1 6}}$ As shown in Fig. 2, the solid sample of luminogen 1 was surveyed by scanning electron microscope (SEM), and the SEM image demonstrated the possible crystalline character of the corresponding solid powder. Next, the solid-state emission lifetime of 1 was tested. As presented in Fig. 3, the roomtemperature solid-state emission lifetime of $\mathbf{1}$ was as high as $29.91 \mathrm{~ms}$. Thus, the luminescence of $\mathbf{1}$ belonged to a long RTP emission. ${ }^{17}$ Multiple weak intermolecular interactions and intermolecular gold-gold interactions possible promote the formation of room-temperature phosphorescence behavior. ${ }^{18}$

Subsequently, the mechanochromic behavior of $\mathbf{1}$ was investigated by solid-state photoluminescence (PL) spectroscopy. As shown in Fig. 4, the luminescence spectrum of solid sample 1 showed two emission bands with $\lambda_{\max }$ at $436 \mathrm{~nm}$, $460 \mathrm{~nm}, 546 \mathrm{~nm}$ and $594 \mathrm{~nm}$, corresponding to a bright yellow emission under irradiation with $365 \mathrm{~nm}$ UV light. Interestingly, after mechanical grinding using a mortar, the yellow-emitting solid sample is changed into a yellow-green-emitting solid

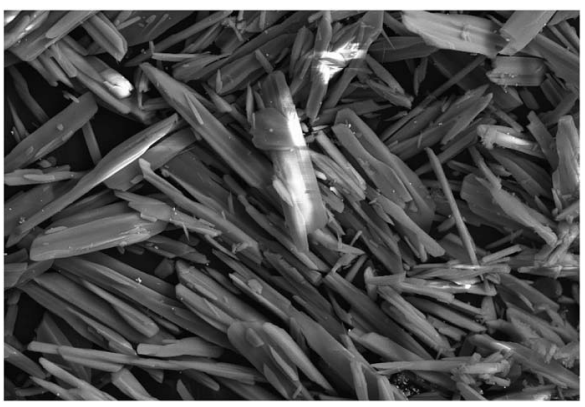

Fig. 2 SEM image $(20 \mu \mathrm{m})$ of the solid sample 1.

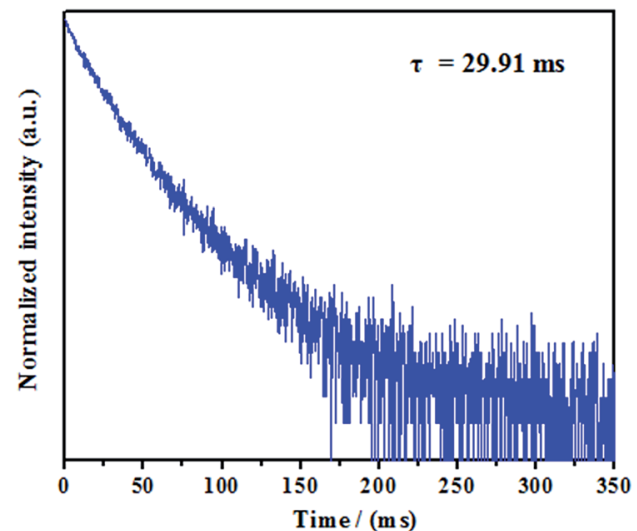

Fig. 3 Decay curve of emission at $546 \mathrm{~nm}$. Delay time $=0.2 \mathrm{~ms}$. Excitation wavelength: $365 \mathrm{~nm}$.

sample, and two emission bands with $\lambda_{\max }$ at $468 \mathrm{~nm}, 546 \mathrm{~nm}$ and $594 \mathrm{~nm}$ were observed.

After fuming with dichloromethane solvent vapor for $30 \mathrm{~s}$, the initial intense yellow luminescence reappeared. In addition, this mechanochromic luminescence transition of $\mathbf{1}$ can be repeated many times between the yellow luminescence and yellow-green luminescence by alternating grinding and fuming processes (Fig. 5). More importantly, as can be seen in Fig. 6, the yellow-green-emitting solid powder can be robustly selfrecovered back to yellow-emitting solid powder within $10 \mathrm{~h}$, and two new emission bands with $\lambda_{\max }$ at $472 \mathrm{~nm}, 564 \mathrm{~nm}$ and $596 \mathrm{~nm}$ can be observed clearly. This self-reversible mechanochromic phenomenon is very beneficial for realizing volatile optical memory.

It is conjectured that the corresponding mechanochromic mechanism should be related with the transformation of molecular morphology. In order to further verify this proposed mechanism responsible for the observed mechanochromism phenomenon, the structural transformation of the powder sample of luminogen 1 was tested by X-ray diffraction (XRD) measurements. As shown in Fig. 7, the XRD pattern for the freshly synthesized form of $\mathbf{1}$ exhibited a lot of sharp and intense peaks, which suggested the crystalline nature of the

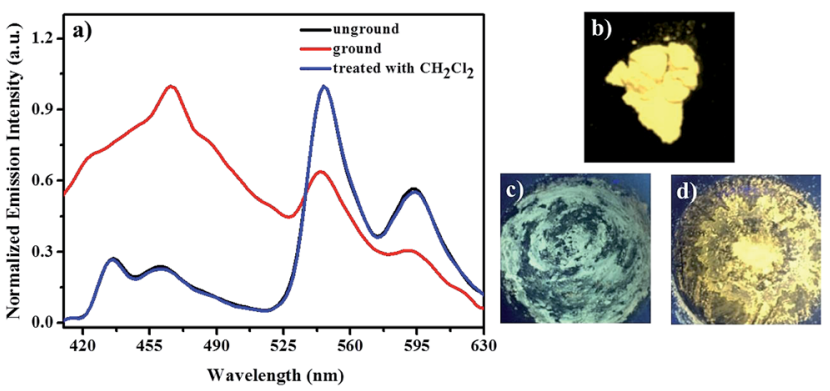

Fig. 4 (a) PL spectra of complex 1 before grinding, after grinding, and after treatment with dichloromethane vapor. Excitation wavelength: $365 \mathrm{~nm}$. Photographic images of luminogen 1 under $365 \mathrm{~nm}$ UV light: (b) the as-synthesized sample. (c) The entirely ground sample. (d) The sample after treatment with dichloromethane vapor. 


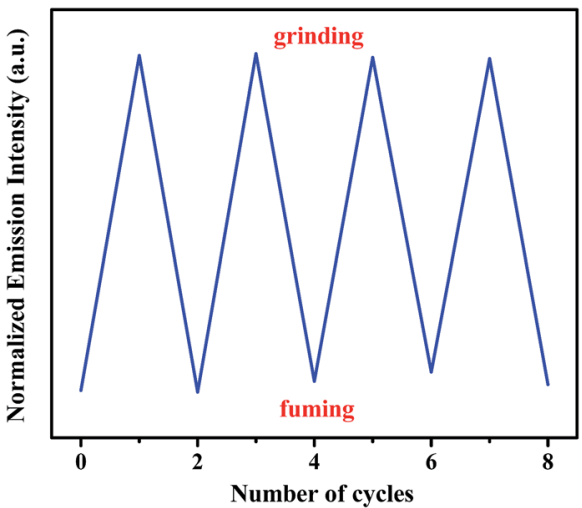

Fig. 5 Reversible grinding-fuming processes of the photoluminescence of complex 1 at $468 \mathrm{~nm}$.

initial solid sample. As a consequence, 1 exhibited obvious crystallization-induced emission enhancement (CIEE) behavior. In contrast, after grinding, the intense crystalline peaks disappeared and a pattern with weak diffraction peaks was observed, indicating the amorphous nature of the ground sample. Moreover, upon treatment of ground solid sample 1 with dichloromethane solvent vapor, the recovery of the amorphous-to-crystal phase could be realized. Hence, the powder XRD measurement results indicate that the mechanochromic property of $\mathbf{1}$ is due to the switchable morphology transition between the crystalline and amorphous phases.

In summary, a carbazole-based gold(I) complex was synthesized. This luminogen exhibits a bright yellow luminescence and a long RTP lifetime, which is as high as $29.91 \mathrm{~ms}$. Furthermore, it also shows reversible mechanochromic behavior involving the luminescence changes between yellow and yellow-green emissions. More interestingly, the mechanochromic yellow-green luminescence of $\mathbf{1}$ can be restored to the initial yellow color spontaneously without using other stimuli. To the best of our knowledge, this carbazole-based mononuclear $\operatorname{gold}(\mathrm{I})$ complex is the first example of metal-bearing luminogen with a long RTP lifetime and self-reversible mechanochromic behavior. Further studies on the design of new

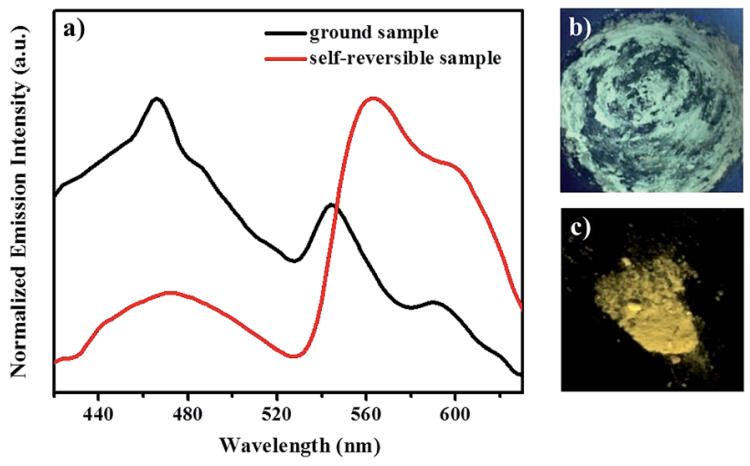

Fig. 6 (a) PL spectra of complex 1 at different conditions. Excitation wavelength: $365 \mathrm{~nm}$. Photographic images of luminogen 1 under $365 \mathrm{~nm}$ UV light: (b) the entirely ground sample; (c) $10 \mathrm{~h}$ after grinding.

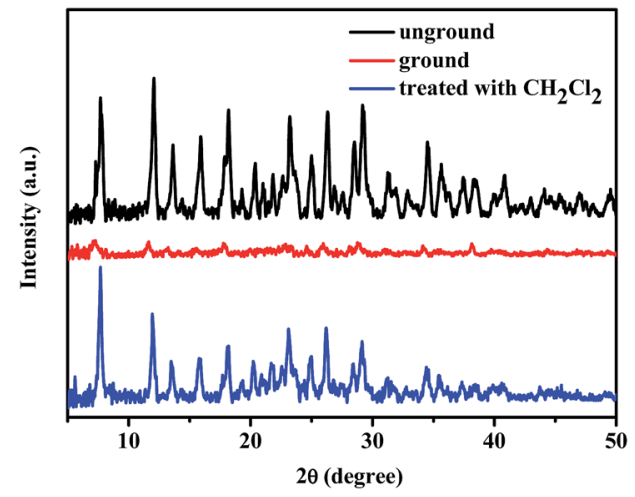

Fig. 7 XRD patterns of luminogen 1: unground, ground and after treatment with dichloromethane vapor.

luminogens with a long RTP lifetime and self-reversible multistimuli responsive behaviors are in progress.

\section{Acknowledgements}

The authors are grateful for the financial support from the National Natural Science Foundation of China (51373072, 201362013, 21662015, and 21262015), the Project of Jiangxi SciTech Innovative Team (20142BCB24012), the Science Fund of Natural Science Foundation of Jiangxi Province (20142BAB203005), and the Project of the Science Fund of Jiangxi Education Office (GJJ160764).

\section{Notes and references}

1 (a) A. C. Grimsdale, K. L. Chan, R. E. Martin, P. G. Jokisz and A. B. Holmes, Chem. Rev., 2009, 109, 897-1091; (b) Y. Hong, J. W. Y. Lam and B. Z. Tang, Chem. Soc. Rev., 2011, 40, 5361-5388; (c) J. Mei, Y. Hong, J. W. Y. Lam, A. Qin, Y. Tang and B. Z. Tang, Adv. Mater., 2014, 26, 5429-5479; (d) Z. Chen, D. Wu, X. Han, J. Liang, J. Yin, G.-A. Yu and S. H. Liu, Chem. Commun., 2014, 50, 11033-11035; (e) Z. Chen, D. Wu, X. Han, Y. Nie, J. Yin, G.-A. Yu and S. H. Liu, RSC Adv., 2014, 4, 63985-63988; (f) Z. Chen, J. Liang, X. Han, J. Yin, G.-A. Yu and S. H. Liu, Dyes Pigm., 2015, 112, 59-66; $(g)$ Z. Chen, X. Han, J. Zhang, D. Wu, G.-A. Yu, J. Yin and S. H. Liu, RSC Adv., 2015, 5, 15341-15349. 2 (a) Z. Chi, X. Zhang, B. Xu, X. Zhou, C. Ma, Y. Zhang, S. Liu and J. Xu, Chem. Soc. Rev., 2012, 41, 3878-3896; (b) G.-G. Shan, H.-B. Li, J.-S. Qin, D.-X. Zhu, Y. Liao and Z.-M. Su, Dalton Trans., 2012, 41, 9590-9593; (c) X. Zhang, Z. Chi, Y. Zhang, S. Liu and J. Xu, J. Mater. Chem. C, 2013, 1, 3376-3390; (d) S. Xue, X. Qiu, Q. Sun and W. Yang, J. Mater. Chem. C, 2016, 4, 1568-1578.

3 M.-J. Teng, X.-R. Jia, S. Yang, X.-F. Chen and Y. Wei, $A d v$. Mater., 2012, 24, 1255-1261.

4 (a) Y. Qi, Y. Wang, Y. Yu, Z. Liu, Y. Zhang, G. Du and Y. Qi, RSC Adv., 2016, 6, 33755-33762; (b) H.-J. Kim, D. R. Whang, J. Gierschner, C. H. Lee and S. Y. Park, Angew. Chem., Int. Ed., 2015, 54, 4330-4333. 
5 (a) Y. Dong, B. Xu, J. Zhang, X. Tan, L. Wang, J. Chen, H. Lv, S. Wen, B. Li, L. Ye, B. Zou and W. Tian, Angew. Chem., Int. Ed., 2012, 51, 10782-10785; (b) R. Misra, T. Jadhav, B. Dhokale and S. M. Mobin, Chem. Commun., 2014, 50, 9076-9078; (c) G.-F. Zhang, M. P. Aldred, Z.-Q. Chen, T. Chen, X. Meng and M.-Q. Zhu, RSC Adv., 2015, 5, 10791082; (d) B. Xu, J. He, Y. Mu, Q. Zhu, S. Wu, Y. Wang, Y. Zhang, C. Jin, C. Lo, Z. Chi, A. Lien, S. Liu and J. Xu, Chem. Sci., 2015, 6, 3236-3241; (e) J. Wei, B. Liang, X. Cheng, Z. Zhang, H. Zhang and Y. Wang, RSC Adv., 2015, 5, 71903-71910; (f) J. Yang, Q. Guo, X. Wen, X. Gao, Q. Peng, Q. Li, D. Ma and Z. Li, J. Mater. Chem. C, 2016, 4, 8506-8513; (g) R. M. Ongungal, A. P. Sivadas, N. S. Saleesh Kumar, S. Menon and S. Das, J. Mater. Chem. C, 2016, 4, 9588-9597.

6 (a) W. J. Hunks, M. C. Jennings and R. J. Puddephatt, Inorg. Chem., 2000, 39, 2699-2702; (b) G. J. Hutchings, M. Brust and H. Schmidbaur, Chem. Soc. Rev., 2008, 37, 1759-1765; (c) R. Benavente, P. Espinet, S. Lentijo, J. M. Martín-Álvarez, J. A. Miguel and M. P. Rodríguez-Medina, Eur. J. Inorg. Chem., 2009, 2009, 5399-5406; (d) W. Lu, W.-M. Kwok, C. Ma, C. T.-L. Chan, M.-X. Zhu and C.-M. Che, J. Am. Chem. Soc., 2011, 133, 14120-14135; (e) E. R. T. Tiekink, Coord. Chem. Rev., 2014, 275, 130-153.

7 (a) M. Osawa, I. Kawata, S. Igawa, M. Hoshino, T. Fukunaga and D. Hashizume, Chem.-Eur. J., 2010, 16, 12114-12126; (b) H. Ito, M. Muromoto, S. Kurenuma, S. Ishizaka, N. Kitamura, H. Sato and T. Seki, Nat. Commun., 2013, 4, 2009-2013; (c) T. Seki, K. Sakurada and H. Ito, Angew. Chem., Int. Ed., 2013, 52, 12828-12832; (d) P. Baranyai, G. Marsi, C. Jobbágy, A. Domján, L. Oláh and A. Deák, Dalton Trans., 2015, 44, 13455-13459; (e) T. Seki, T. Ozaki, T. Okura, K. Asakura, A. Sakon, H. Uekusa and H. Ito, Chem. Sci., 2015, 6, 2187-2195.

8 (a) H. Ito, T. Saito, N. Oshima, N. Kitamura, S. Ishizaka, Y. Hinatsu, M. Wakeshima, M. Kato, K. Tsuge and M. Sawamura, J. Am. Chem. Soc., 2008, 130, 10044-10045; (b) J. Liang, F. Hu, X. Lv, Z. Chen, Z. Chen, J. Yin, G.-A. Yu and S. H. Liu, Dyes Pigm., 2012, 95, 485-490; (c) J. Liang, Z. Chen, L. Xu, J. Wang, J. Yin, G.-A. Yu, Z.-N. Chen and S. H. Liu, J. Mater. Chem. C, 2014, 2, 2243-2250; (d) Z. Chen, P.-S. Huang, Z. Li, J. Yin, G.-A. Yu and S. H. Liu,
Inorg. Chim. Acta, 2015, 432, 192-197; (e) Z. Chen, J. Zhang, M. Song, J. Yin, G.-A. Yu and S. H. Liu, Chem. Commun., 2015, 51, 326-329; (f) Z. Chen, Z. Li, L. Yang, J. Liang, J. Yin, G.-A. Yu and S. H. Liu, Dyes Pigm., 2015, 121, 170177; $(g)$ Z. Chen, Y. Nie and S. H. Liu, RSC Adv., 2016, 6, 73933-73938.

9 (a) H. Huang, Y. Wang, B. Wang, S. Zhuang, B. Pan, X. Yang, L. Wang and C. Yang, J. Mater. Chem. C, 2013, 1, 5899-5908; (b) C. Tang, R. Bi, Y. Tao, F. Wang, X. Cao, S. Wang, T. Jiang, C. Zhong, H. Zhang and W. Huang, Chem. Commun., 2015, 51, 1650-1653.

10 J. Mei, N. L. C. Leung, R. T. K. Kwok, J. W. Y. Lam and B. Z. Tang, Chem. Rev., 2015, 115, 11718-11940.

11 (a) Z. Chen, L. Yang, Y. Hu, D. Wu, J. Yin, G.-A. Yu and S. H. Liu, RSC Adv., 2015, 5, 93757-93764; (b) Z. Chen, J. Liang, Y. Nie, X. Xu, G.-A. Yu, J. Yin and S. H. Liu, Dalton Trans., 2015, 44, 17473-17477; (c) Z. Chen, Z. Li, F. Hu, G.-A. Yu, J. Yin and S. H. Liu, Dyes Pigm., 2016, 125, 169-178. 12 (a) Z. An, C. Zheng, Y. Tao, R. Chen, H. Shi, T. Chen, Z. Wang, H. Li, R. Deng, X. Liu and W. Huang, Nat. Mater., 2015, 14, 685-690; (b) Y. Gong, G. Chen, Q. Peng, W. Z. Yuan, Y. Xie, S. Li, Y. Zhang and B. Z. Tang, Adv. Mater., 2015, 27, 61956201; (c) P. Xue, J. Sun, P. Chen, P. Wang, B. Yao, P. Gong, Z. Zhang and R. Lu, Chem. Commun., 2015, 51, 10381-10384.

13 P. S. Hariharan, N. S. Venkataramanan, D. Moon and S. P. Anthony, J. Phys. Chem. C, 2015, 119, 9460-9469.

14 D. Tu, P. Leong, Z. Li, R. Hu, C. Shi, K. Y. Zhang, H. Yan and Q. Zhao, Chem. Commun., 2016, 52, 12494-12497.

15 J. Luo, Z. Xie, J. W. Y. Lam, L. Cheng, H. Chen, C. Qiu, H. S. Kwok, X. Zhan, Y. Liu, D. Zhu and B. Z. Tang, Chem. Commun., 2001, 1740-1741.

16 J. Liang, Z. Chen, J. Yin, G.-A. Yu and S. H. Liu, Chem. Commun., 2013, 49, 3567-3569.

17 (a) M. Osawa, I. Kawata, S. Igawa, A. Tsuboyama, D. Hashizume and M. Hoshino, Eur. J. Inorg. Chem., 2009, 2009, 3708-3711; (b) Z. Yang, Z. Mao, X. Zhang, D. Ou, Y. Mu, Y. Zhang, C. Zhao, S. Liu, Z. Chi, J. Xu, Y.-C. Wu, P.-Y. Lu, A. Lien and M. R. Bryce, Angew. Chem., Int. Ed., 2016, 55, 2181-2185.

18 G. Bergamini, A. Fermi, C. Botta, U. Giovanella, S. D. Motta, F. Negri, R. Peresutti, M. Gingras and P. Ceroni, J. Mater. Chem. C, 2013, 1, 2717-2724. 